\title{
Occupational paternal exposure to benzene and risk of spontaneous abortion
}

\author{
I Stücker, L Mandereau, M P Aubert-Berleur, F Déplan, A Paris, A Richard, D Hémon
}

\begin{abstract}
Objective-The purpose of this study was to evaluate the risk of spontaneous abortion among the wives of male workers occupationally exposed to benzene. Methods-The wives of 823 men working in two chemical plants at the time of the study were asked to complete a questionnaire describing their pregnancies. The analysis of the 1739 pregnancies that ended in a spontaneous abortion or a birth is presented. The firms' payroll records provided all workers' employment history, including dates. Benzene exposure, graded at two levels $(<5, \geqslant 5$ ppm), was determined for every job, so that benzene exposure for each worker's entire professional life (at these companies) could be assessed. This information was linked to the dates of the pregnancies reported in the questionnaires to enable the exposure status of each pregnancy to be defined (1270 non-exposed and 274 exposed). The frequency of spontaneous abortion, defined as the number of spontaneous abortions divided by the total of spontaneous abortions and births was evaluated.
\end{abstract}

Results-When adjusted for tobacco consumption, mother's age and pregnancy order, the odds ratio of the association between paternal exposure to approximately $5 \mathrm{ppm}$ of benzene and the risk of spontaneous abortion was close to and statistically not different from unity (OR $=1 \cdot 1 ; 95 \%$ CI $(0 \cdot 7-1 \cdot 8)$.

Conclusion-In this study paternal exposure to benzene did not increase the risk of spontaneous abortion.

Enité de Recherches Statistiques sur

l'Environnement

et la Santé

(Epidemiological and

Statistical Research

on Environment and

Health), INSERM U

170, 16 Avenue Paul-

Vaillant Couturier,

94807 Villejuif cedex,

France

I Stücker

L Mandereau

M P Aubert-Berleur

D Hémon

Rhône-Poulenc

Chimie, BP150

Roussillon, France

A Paris

A Richard

Correspondence to:

Dr I Stücker.

Accepted for publication

5 April 1994 however, involve subjects exposed to moderate or low concentrations, and fail to show such an effect. ${ }^{3-6}$

With regard to reproductive effects, one study isolated benzene among the different organic solvent exposures and found a nonsignificant excess of spontaneous abortion. ${ }^{7}$ Paternal exposure to solvents has been studied far less. Several studies have found an association with congenital problems, particularly CNS malformations and cleft palate. ${ }^{8}$ Three reports deal with spontaneous abortions. Two of them found no association. ${ }^{910}$ By contrast, the study of Taskinen et al found a significant excess in the frequency of spontaneous abortion and paternal exposure 80 days before conception. ${ }^{11}$ These results primarily involved toluene and miscellaneous solvents.

The study we performed aimed at evaluating the risk of spontaneous abortion in relation to paternal exposure to benzene. It took place in France at two large factories involved in organic processes.

\section{Materials and methods}

The study took place in two organic chemical factories, A and B, located in the Rhone Alpes region of France, and belonging to two companies. It concerned all the married men under 45 years old employed there at the time of the study $(n=1077)$. The list of employees was drawn up by the companies' occupational physicians. Information about sociodemographic characteristics and pregnancies were obtained by a two part questionnaire, one part completed by the employee, the other part by his wife. Each part contained questions about sociodemographic characteristics, lifestyle, and habits (coffee, wine, and tobacco use, etc). Employees were also asked about previous jobs. Questions related to pregnancies were asked only of the wives, and were answered by them at home. The questionnaire requested a description of each pregnancy (outcome and date of the issue) as well as information about the classic risk factors related to spontaneous abortions (pregnancy order, mother's age during pregnancy, and cigarette smoking). It also asked about the method by which the pregnancy was diagnosed (laboratory examination, pharmaceutical test, physician's examination, or late menstrual period), the number of weeks of gestation at abortion, and any admission to hospital or curettage, to permit an assessment of the reliability of the spontaneous abortions reported. 
The questionnaires were mailed directly to our laboratory in such a way that the companies could not discover who had and who had not cooperated in the study. The employees' occupational histories, including a list of all jobs held in the companies (and corresponding dates), were provided by the companies' personnel department.

EVALUATION OF BENZENE EXPOSURE BY JOBS The occupational physicians listed all the functions performed in every department and assigned each to one of three levels of benzene exposure: none ( $0 \mathrm{ppm})$, low (1-5 ppm), and moderate $(\geqslant 5 \mathrm{ppm})$. These estimations were established taking into account the special benzene monitoring provided to employees of some departments, the results of environmental analyses previously performed, the evolution of various processes used within the companies, and new protective equipment in different departments.

EVALUATION OF EXPOSURE OF PREGNANCIES

Dates of conception were estimated using, for a birth, the due date minus the gestation period ( 40 weeks) or, for a spontaneous abortion, its date minus the term of the pregnancy at that time. Two different types of paternal exposure for each pregnancy were defined: exposure in the three months immediately before conception, and any past exposure. Despite some imprecision in the dates estimated, there were only a few job transfers during the year of pregnancy that resulted in the pregnancy being classified as exposed.

\section{CONFOUNDERS}

Age of the mother and father at the end of the pregnancy, pregnancy order, number of previous spontaneous abortions, and maternal tobacco use were determined by responses to the questionnaire. Plant employees might also have been exposed to other chemical substances such as chlorohydric or acetic acids, to physical factors such as heat and magnetic fields, or to materials such as bleach. Nevertheless, because none of these are presently considered to be a risk factor for spontaneous abortion, they were not considered as potential confounders in this analysis.

Table 1 Means (SD) of selected sociodemographic variables for workers and their wives, by plant

\begin{tabular}{llll}
\hline Characteristic sociodemographic variables & Plant $A$ & Plant $B$ & Total \\
\hline Workers (No) & 434 & 389 & 823 \\
Age at interview (y) & $37 \cdot 3(5 \cdot 6)$ & $41 \cdot 1(5 \cdot 4)$ & $39 \cdot 1(5 \cdot 8)$ \\
Years worked in the plant & $(\mathrm{n}=430)$ & $(\mathrm{n}=384)$ & $(\mathrm{n}=814)$ \\
Spouses: & $13 \cdot 1(6 \cdot 8)$ & $17 \cdot 4(6 \cdot 9)$ & $15 \cdot 2(7 \cdot 2)$ \\
Age (y) & $(\mathrm{n}=411)$ & $(\mathrm{n}=385)$ & $(\mathrm{n}=796)$ \\
No of pregnancies per woman & $35 \cdot 0(6 \cdot 1)$ & $39 \cdot 2(6 \cdot 2)$ & $37 \cdot 0(6 \cdot 5)$ \\
& $(\mathrm{n}=412)$ & $(\mathrm{n}=387)$ & $(\mathrm{n}=799)$ \\
No of babies per woman & $(\mathrm{n}=4 \cdot \mathrm{1})$ & $2 \cdot 3(1 \cdot 2)$ & $2 \cdot 1(1 \cdot 2)$ \\
& $1 \cdot 8(1 \cdot 0)$ & $(\mathrm{n}=389)$ & $(\mathrm{n}=823)$ \\
Pregnancies: & $(\mathrm{n}=434)$ & $(\mathrm{n}=389)$ & $1 \cdot 9(1 \cdot 0)$ \\
Mother's age at delivery (y) & $25 \cdot 4(4 \cdot 1)$ & $25 \cdot 7(4 \cdot 5)$ & $25 \cdot 5(4 \cdot 3)$ \\
& $(\mathrm{n}=845)$ & $(\mathrm{n}=880)$ & $(\mathrm{n}=1725)$ \\
Pregnancy order & $1 \cdot 8(1 \cdot 0)$ & $1 \cdot 9(1 \cdot 1)$ & $1 \cdot 9(1 \cdot 1)$ \\
Interval since delivery (y) & $11 \cdot 0(5 \cdot 7)$ & $14 \cdot 4(6 \cdot 0)$ & $12 \cdot 7(6 \cdot 1)$ \\
Infants' birthweight $(\mathrm{g})$ & $3327(507)$ & $3296(492)$ & $3311(499)$ \\
\hline
\end{tabular}

\section{OUTCOME}

A spontaneous abortion was defined as a pregnancy that ended before 28 weeks of gestation. Induced abortions were excluded from the analysis to avoid the problem of their being under-reported. Therefore, frequency of spontaneous abortions was defined as the number of spontaneous abortions over the number of pregnancies, excluding induced abortions.

POWERS

If we assume that the frequency of spontaneous abortions lies between $10 \%$ and $15 \%$, a minimum of 200 pregnancies per group was required to detect a twofold increase in risk with a power larger than or equal to $80 \%$.

\section{STATISTICAL ANALYSIS}

In the statistical analyses, multiple pregnancies to the same woman were treated as statistically independent, although this is not strictly true. A separate analysis was performed for first pregnancies only, to take into account the variability in the risk of spontaneous abortion among women.

All the estimates were done on a VAX (digital equipment). Statistical analysis software was used for all the univariate analysis and adjustment for one confounder. Estimates calculated were relative risks (RRs) with their 95\% confidence intervals (95\% CIs). Simultaneous adjustment on several confounders was done by logistic regression, with BMDP software. The odds ratio (OR) and $95 \%$ CIs were calculated with the formulae: $O R=\exp (\beta)$ coefficient; $95 \%$ CI: lower limit $=\exp (\beta-\operatorname{SE}(\beta) \times 1.96)$, upper limit $=$ $\exp (\beta+\operatorname{SE}(\beta) \times 1.96)$.

\section{Results}

Of 1077 employees eligible for the study, 254 refused to participate. Table 1 describes the age at the time of response to the questionnaire, years worked in the plants, number of pregnancies, and births per woman by plant. Of 1739 pregnancies described, 171 ended in a spontaneous abortion (rate $=9 \cdot 8 \%$ ). The infants' mean birthweight was 3311 (SEM 12) g.

According to the categories of exposure described, 1277 pregnancies were defined as non-exposed, and 270 as exposed at some time before conception. Among the 270, 145 were exposed during the three months immediately preceding conception. Imprecision about the date of conception or the work assignment around that date made it impossible to define the exposure state of 188 pregnancies; for four pregnancies, the exposure state was unknown only for the three month period immediately before conception. The frequency of spontaneous abortion was not significantly higher in the group exposed at any time before conception $(11.3 \%)$ than in the non-exposed group $(8.8 \%),(R R=1.3$ (95\% CI $0.9-2 \cdot 0)$; nor was it higher $(9.9 \%)$ for the group exposed during the three months immediately before conception $(\mathrm{RR}=$ $1 \cdot 1(95 \%$ CI $0 \cdot 6-2 \cdot 0)$. 
Table 2 Frequency of spontaneous abortion, according to classic risk factors

\begin{tabular}{|c|c|c|c|}
\hline Risk factors & Category at low risk & Category at high risk & $R R(95 \% C I)$ \\
\hline Mother's age at delivery (y) & $\begin{array}{l}<30 y \\
9 \%(1407)\end{array}$ & $\begin{array}{l}\geqslant 30 y \\
13.9 \%(317)\end{array}$ & $1 \cdot 6(1 \cdot 1-2 \cdot 3)$ \\
\hline Pregnancy order & $\begin{array}{l}<3 \\
8.7 \%(1353)\end{array}$ & $\begin{array}{l}\geqslant 3 \\
13 \cdot 7 \%(386)\end{array}$ & $1 \cdot 7(1 \cdot 2-2 \cdot 3)$ \\
\hline Tobacco consumption & $\begin{array}{l}\text { Non-smoker } \\
9 \cdot 8 \%\end{array}$ & $\begin{array}{l}\text { Smoker } \\
11 \cdot 0 \%\end{array}$ & $1 \cdot 1(0 \cdot 8-1 \cdot 6)$ \\
\hline
\end{tabular}

Numbers of pregnancies are in parentheses.

Relations between classic risk factors and the frequency of spontaneous abortions were studied in this sample. The mother's age and pregnancy order were significantly higher for pregnancies that ended in a spontaneous abortion than for those leading to a birth. Tobacco consumption during the year of the pregnancy was also slightly higher for that group, but not significantly so (table 2 ). The relation found between the father's age and spontaneous abortions actually reflected the relation with the mother's age. The results obtained were therefore adjusted separately for the mother's age, pregnancy order, and tobacco consumption. The association between benzene exposure and spontaneous abortion was not modified in any of these cases. Adjustment for all three confounders simultaneously in a logistic regression decreased the OR to $1 \cdot 1$ (95\% CI $0 \cdot 7-1 \cdot 8)$ when any past exposure was considered and to $0.9(95 \%$ CI $0.4-1 \cdot 7)$ for exposure during the three months immediately preceding conception.

In a second step we considered each woman's first pregnancy only: 583 were classified as non-exposed, 54 as exposed during the three months preceding conception, and 106 exposed at any time in the past. The frequency of abortion was similar for each group, and adjustment on the different risk factors, considered separately or simultaneously in a logistic regression, did not modify these results.

We also examined the relation of the spontaneous abortions to two levels of benzene exposure: less than $5 \mathrm{ppm}$ (low) and $\geqslant 5 \mathrm{ppm}$ (moderate) (table 3 ). When any past exposure was considered, the crude $R R$ was slightly higher for the moderate level of exposure than for the low level. This increase was, however, totally explained by the classic risk factors as shown by the adjusted analysis. Nor was the test for linear trend significant, for either the

Table 3 Frequency of spontaneous abortion according to the level and period of benzene exposure

\begin{tabular}{|c|c|c|c|c|c|}
\hline Type of exposure & $\begin{array}{l}\text { Non-exposed } \\
\text { pregnancies }\end{array}$ & $\begin{array}{l}\text { Exposed } \\
\text { pregnancies } \\
<5 \text { ppm }\end{array}$ & $\begin{array}{l}\text { Exposed } \\
\text { pregnancies } \\
\geqslant 5 \text { ppm }\end{array}$ & $\begin{array}{l}\text { ORI } \\
(95 \% C I)\end{array}$ & $\begin{array}{l}\text { OR2 } \\
(95 \% \text { CI })\end{array}$ \\
\hline All past exposures & $\begin{array}{l}8 \cdot 8 \% \\
(1277)\end{array}$ & $\begin{array}{l}9 \cdot 6 \% \\
(114)\end{array}$ & $\begin{array}{l}12 \cdot 5 \% \\
(160)\end{array}$ & $\begin{array}{l}1 \cdot 0 \\
(0 \cdot 5-2 \cdot 0)\end{array}$ & $\begin{array}{l}1 \cdot 2 \\
(0 \cdot 7-2 \cdot 1)\end{array}$ \\
\hline $\begin{array}{l}\text { Exposure during } \\
\text { three months } \\
\text { before conception }\end{array}$ & $\begin{array}{l}8 \cdot 8 \% \\
(1277)\end{array}$ & $\begin{array}{l}11 \cdot 8 \% \\
(68)\end{array}$ & $\begin{array}{l}7 \cdot 8 \% \\
(77)\end{array}$ & $\begin{array}{l}1 \cdot 1 \\
(0 \cdot 5-2 \cdot 7)\end{array}$ & $\begin{array}{l}0.7 \\
(0 \cdot 3-1 \cdot 7)\end{array}$ \\
\hline
\end{tabular}

OR1 = Odds ratio related to exposure $<5$ ppm adjusted for age of the mother, pregnancy order and tobacco consumption. $O R 2=$ Odds ratio related to exposure $\geqslant 5 \mathrm{ppm}$ adjusted for age of the mother, pregnancy order, and tobacco consumption. Numbers of pregnancies are in parenthe mothes.
theses crude or the adjusted OR. Similar results were reached when only the three months period immediately preceding conception was considered.

Finally, we distributed the pregnancies exposed to a level $\geqslant 5 \mathrm{ppm}(\mathrm{n}=160)$ into four categories as equal as possible, according to the duration of exposure. Thirty pregnancies had been exposed to such a level during more than five years and exhibited a frequency of spontaneous abortion of $13.3 \%$. This slight excess was, however, totally explained by the confounders (adjusted $\mathrm{OR}=$ $0.93(0.3-3 \cdot 01)$.

\section{Discussion}

This investigation studied the frequency of spontaneous abortions in relation to paternal exposure to benzene. Two periods of exposure were examined: all exposures before conception, and that during the three months immediately before conception. No significant relation was found for either period of exposure. Nor were the results modified when we took into account the level of exposure $(<5$ or $\geqslant 5 \mathrm{ppm}$ ). Finally we isolated the pregnancies most heavily exposed for the longest time period, but no significant excess after adjustment for classic risk factors was found.

Our sample consisted of all pregnancies of the wives of men employed in two organic chemical plants. The rate of spontaneous abortion for the entire study population was $9 \cdot 8 \%$. This result is very close to the well known spontaneous abortion rate $(10-15 \%)$ for clinically recognised pregnancies. We also found an excess of spontaneous abortion related to mother's age at the end of pregnancy and to the pregnancy order, both classic risk factors. We found, too, an excess of spontaneous abortion related to tobacco consumption; it was not, however, significant. This may be explained by the fact that the questions concerned lifetime smoking habits but not specifically during pregnancy. Another study involving the same population and using the same questionnaire found a significant excess of spontaneous abortion related to exposure to mercury. ${ }^{12}$

Our study took place in a context where the existence of a link between paternal exposure to solvents and the frequency of spontaneous abortion has been shown in one of three studies. ${ }^{9-11}$ Furthermore, to our knowledge, the present study is the only one that focuses on a particular solvent.

All the pregnancies that occurred before the employee started work in the plant are considered as non-exposed. To verify that such pre-employment pregnancies do not for any reason increase the rate of spontaneous abortions in the non-exposed group, we compared, within that group, the frequency of spontaneous abortions between the preemployment and employment pregnancies. The frequency of spontaneous abortions between the two groups was similar.

Exposure assessments were made by the occupational physicians, with the results of 
atmospheric measurements taken over the past 20 years, as well as a special departmental benzene monitoring. This procedure might, however, lead to misclassification, especially because the measurements were not taken on a regular basis, so that the exposure level was sometimes established by extrapolation. But, because no connection could exist between the exposure assessment and the data about the pregnancies, these misclassifications would only result in a loss of power.

Classic risk factors have been taken into account in the analysis, and adjustment on them leads to an estimate of the adjusted OR close to unity. Also, because considering every pregnancy of each woman may overemphasise a few women who experienced a substantial number of spontaneous abortions, first pregnancies were analysed separately. This again, resulted in an OR close to unity for either period of exposure.

If we assume that the mechanism linking paternal exposure and spontaneous abortion goes through mutational events on germinal cells, two types of germ cells might be affected: the stem cells, on the one hand and cells involved in the spermatogenesis process on the other. Because we had no a priori hypothesis about which germinal cells could be affected by the benzene, we first considered all benzene exposure before pregnancy. The results did not suggest any increased risk related to benzene. In a second step, we restricted the exposure period to the three months immediately preceding the pregnancy, to avoid diluting any potential effect, if the cells affected were more specifically those involved in spermatogenesis. No substantial modification at all was found.

We were able to assess exposure state for 1547 pregnancies. At some time in the past, $17 \cdot 7 \%$ were exposed, or $9 \cdot 4 \%$, if exposure were restricted to the three months immediately preceding the pregnancy. If we assume a twofold increase in spontaneous abortions related to benzene exposure, the study has a statistical power of $85 \%$. This power has been estimated, however, without taking into account the relative proportions of spontaneous abortion connected to chromosomal abnormalities of either parent. This consideration would certainly have decreased the power.

In conclusion, when adjusted for tobacco consumption, mother's age and pregnancy order, the OR of the association between paternal exposure to about $5 \mathrm{ppm}$ of benzene and the risk of spontaneous abortion was close to, and statistically not different from unity $(\mathrm{OR}=1 \cdot 1,95 \% \mathrm{CI} 0 \cdot 7-1 \cdot 8)$.

We are grateful to Dr Jean Claude Aubrun of Rhône-Poulenc Industries whose efficient assistance was indispensable in the initial steps of this work and to Jo Ann Cahn for help in revising the manuscript.

1 International Agency of Research on Cancer (IARC). Benzene. IARC Monogr Eval Carcinog Risks Hum 1987; 29:93-148.

2 Kalf GF. Recent advances in the metabolism and toxicity of benzene. Crit Rev Toxicol 1987;18:141-59.

3 Jablonicka A, Vargova M, Karelova J. Cytogenetic analysis of peripheral blood lymphocytes in workers exposed to of peripheral blood lymphocytes in workers exposed to benzene.

4 Yardley-Jones A, Anderson D, Jenkison PC, Lovell DP Blowers SD, Davies MJ. Genotoxic effects in peripheral Blowers SD, Davies MJ. Genotoxic effects in periphera
blood and urine of workers exposed to low level benzene. $B r \mathcal{F}$ Ind Med 1988;45:694-700.

5 Yardley-Jones A, Anderson D, Lovell DP, Jenkison PC. Analysis of chromosomal aberrations in workers exposed to low level benzene. Br f Ind Med 1990;47:48-51.

6 Seiji K, Jin C, Watanabe T, Nakatsuka H, Ikeda M. Sister chromatid exchange in peripheral lymphocytes of workers exposed to benzene, trichloroethylene, with references to smoking habits. Int Arch Occup Environ Health 1990;62: 171-6.

7 Taskinen HK, Lindbohm ML, Hemminki K. Spontaneous abortions among women working in the pharmaceutical abortions among women working in the pha
industry. Br f Ind Med 1986;43:199-205.

8 Taskinen HK. Effects of parental occupational exposures on spontaneous abortion and congenital malformation. on spontaneous abortion and congenital malfo
Scand $₹$ Work Environ Health 1990;16:297-314.

9 Lindbohm ML, Hemminki K, Kyyrönen P. Parental occupational exposure and spontaneous abortions in Finland Am $\mathcal{F}$ Epidemiol 1984;120:449-63.

10 Daniell WE, Vaughan TL. Paternal employment in solvent related occupations and adverse pregnancy outcomes. $B r$ f Ind Med 1988;45:193-7.

11 Taskinen HK, Anttila A, Lindbohm ML, Sallmén M Hemminki $K$. Spontaneous abortions and congenita malformations among the wives of men occupationally exposed to organic solvents. Scand 7 Work Environ Health 1989;15:345-52.

12 Cordier S, Deplan F, Mandereau L, Hémon D. Paternal exposure to mercury and spontaneous abortions. $\mathrm{Br} f$ exposure to mercury and
Ind Med 1991;48:375-81. 